\title{
The Achievements of Engineering Master's Coursework Students from Diverse Backgrounds
}

\author{
Fatihah Suja ${ }^{1,2}$, Zahira Yacob ${ }^{1,3} \&$ Azah Mohammed ${ }^{1,4}$ \\ ${ }^{1}$ Center for Engineering Education Research, Faculty of Engineering and Built Environment, Universiti \\ Kebangsaan Malaysia, Selangor, Malaysia \\ ${ }^{2}$ Department of Civil and Structural Engineering, Faculty of Engineering and Built Environment, Universiti \\ Kebangsaan Malaysia, Selangor, Malaysia \\ ${ }^{3}$ Department of Chemical and Process Engineering, Faculty of Engineering and Built Environment, Universiti \\ Kebangsaan Malaysia, Selangor, Malaysia \\ ${ }^{4}$ Department of Electric, Electronic and Systems Engineering, Faculty of Engineering and Built Environment, \\ Universiti Kebangsaan Malaysia, Selangor, Malaysia \\ Correspondence: Fatihah Suja', Department of Civil and Structural Engineering, Faculty of Engineering and \\ Built Environment, Universiti Kebangsaan Malaysia, 43600 UKM Bangi, Selangor, Malaysia. Tel: \\ 60-3-8921-8428. E-mail: fati@eng.ukm.my
}

Received: September 24, 2012 Accepted: November 7, 2012 Online Published: November 30, 2012

doi:10.5539/ass.v8n16p104

URL: http://dx.doi.org/10.5539/ass.v8n16p104

\begin{abstract}
The objective of this study is to investigate the performance of postgraduate students from various backgrounds on the basis of the following criteria: country, achievements during undergraduate study, English language requirement and previous work experience. The Civil Engineering Master's Programme was taken as a case study. A data set sourced from students' application forms and academic record for three consecutive session intakes, 2008/2009, 2009/2010 and 2010/2011, was used. As a measure of the students' performance, Graduate Cumulative Grade Point Average (GCGPA) was considered as the key performance index. Students from Malaysia (28\%), Iran (53\%) and Iraq (19\%) were chosen because their communities together represent the largest number of students in Malaysia. The mean achievements of the students from Malaysia, Iran and Iraq were comparable (mean GCGPA 3.52-3.60). The largest number of candidates (43.5\%) who entered the programme had an Undergraduate Cumulative Grade Point Average (UCGPA) higher than 2.70 but lower than 3.00. The decision to continue the master's study was most popular with students $1-4$ years after graduation. Regarding the extent to which UCGPA contributed towards GCGPA, Malaysian students exhibited a weak relationship but a stronger correlation than the other student groups $(\mathrm{r}=0.331, p<0.05)$. For Iranian students, work experience was very significant $(\mathrm{r}=0.416, p<0.05)$. The results also indicate that English proficiency affected the performance of the students. The correlation between work experience and GCGPA differed for students with and without TOEFL/IELTS scores. It is hoped that the results of this work can contribute toward a more detailed study for determining the entry requirements of students seeking admission to master's course programmes.
\end{abstract}

Keywords: academic performance, ability, entry levels, background, CGPA

\section{Introduction}

\subsection{Master's by Coursework Students at the Faculty of Engineering and Built Environment}

The Faculty of Engineering and Built Environment at Universiti Kebangsaan Malaysia (UKM) offers six postgraduate programmes for master's by course students. Both local and foreign students can enrol in these programmes. The selection of superior students is an important factor in ensuring good performance by the students. However, it is unlikely that a uniform entry-level selection process can be imposed because the students come from diverse backgrounds.

Because this is a master's programme, the UCGPA, a quality indicator of good candidates, is commonly used for entry selection to graduate programmes. The admission criterion to this programme is a bachelor's degree with honours (minimum CGPA 2.7) from UKM or its equivalent from any other recognised university. Because different countries have different systems for measuring performance, inconsistencies could arise from the 
inequivalence.

The master's programme also accepts applicants with honour degrees with CGPAs of less than 2.7, provided that they possess relevant experience. The question might arise whether greater consideration be given to freshly graduated or to those with short or long periods of experience. One possible performance drawback of candidates who have left school for several years could be the inability to recall the basic fundamentals and theory learned at the undergraduate level. Another drawback could be a decrease in the level of commitment that they can give to their study because most of these senior candidates have more personal responsibility than younger candidates.

Malaysian undergraduates in Malaysian universities have a certain level of English proficiency because they are required to pass the Malaysian University English Test (MUET). TOEFL or IELTS tests could be the best options to assess the level of English of international students. However, this requirement was only implemented in Semester 1, 2009/2010 after realising that many problems occurred due to English insufficiency, as raised by the lecturers involved in the programme.

The study is important to raise preliminary awareness among those involved in the programme and has sparked interest in further examination of the entry requirements that produce better graduates. These findings might differ among programmes but might lead to an improved study that can be used by the university policy decision makers. This paper presents the results of an investigation that compares the performance of master's course students based on their background at entry levels.

\subsection{Civil Engineering Master's Program}

The Master of Engineering (Civil) programme was designed to meet the continual professional development needs of professional engineers and the industry (Self-Assessment Report, 2011). This programme provides an integrated background in civil engineering, which covers the following topics:

1) Structural Engineering and Construction Materials

2) Environmental and Water Resources Engineering

3) Transportation and Geomatic Engineering

4) Geotechnical and Geoenvironmental Engineering

The programme is a $2-4$ semester programme. The curriculum comprises thirty credit units of core courses and six (6) credit units of project thesis. Student academic performance is based on CGPA at each semester. The maximum CGPA is 4.00 . A student must obtain a CGPA of at least 3.00 to be allowed to proceed to the following semester. A student may be allowed to re-sit a course to improve the result of that particular course in the semester when the course is offered. To graduate, a student must have successfully completed 36 credit hour units and obtained a CGPA of at least 3.00.

The programme began with the first batch of students enrolling during the Semester II session of academic year 2004/2005. Initially, five (5) students registered for the programme. Over several years, the programme gained in popularity among foreign students, and the department receives more than 100 applications each year for admission to the programme. However, the programme can only cater to a maximum of 50 students per intake because the number of students that can be taken is limited - by the size of the department. It would be useful if the present entry requirements could be adjusted such that only the best students were selected.

\subsection{Master's Student Performance}

Factors contributing to the students' overall performance include the curriculum, teachers and the students themselves (Arsad, Buniyamin \& Ab Manan, 2011). Assessment based on students' CGPAs is common because this is the most widely known criterion that is used to attract employers' attention in getting calling for an interview. However, other criteria/traits, such as leadership, effective communication skills and interpersonal and entrepreneurial skills are also considered (Academic Regulation, UiTM 2009).

The UCGPA is a student quality indicator that has been consistently used for entry selection into a graduate programme. It has often been questioned whether this factor is a significant contributor to the achievement of master students in their study. Alias and Zain (2006), who conducted a study on the relationship between entry qualifications and performance in graduate education for a Master's degree in the Technical and Vocational Education Programme, concluded that students who entered with high UCGPA tended to graduate with a high CGCPA. However, these authors also reported that Lane, Lane and Cockerton (2003), who carried out a study on hospitality students, found a significant but weak correlation between the class of undergraduate degree and GCGPA $(\mathrm{r}=0.24, p<0.0)$. Lane, Lane and Cockerton (2003) also found that students with first class honours 
degrees down to and upper second class degrees do consistently well in graduate studies whereas those with lesser degrees exhibit varied performance. Alias and Zain (2006) also referred to studies by Kuncel, Hezlett and Ones (2001) and Braunstein (2002), who found similar correlations (i.e., a correlation of 0.3 between UCGPA and GCPA). The finding was also consistent with that of Wardlow (1989), who conducted a study on success in agricultural education for international students studying in the USA and found that the correlation between undergraduate academic ability as rated by academic advisors and CGPA was 0.38. Alias and Zain (2006) also reported that the study of Truitt (2002) on MBAs found no relationship between UCGPA and GCGPA.

Work experience has been considered a selection criterion for students with low CGPA. The effect of previous work experience could be positive or negative because this criterion may be looked at from different perspectives. If the work experience or job is related to the field of study, the fundamentals and theories learned during the undergraduate programme might have been strengthened. However, if the job held by the candidate does not relate to the programme that he/she is going to undergo, the experience could be detrimental. The longer the gap between undergraduate and postgraduate study, the more material the student tends to forget. Additionally, longer work experience could also mean that the candidate may have more personal commitment to his or her private life, thus affecting their performance as a student. Personal life could be a substantial factor that affects the study. De Rue (2009) claimed that 'work experience can be conceptualised along two distinct dimensions: quantity and quality. The quantity dimension refers to an individual's total years of work experience or time with a particular job or organisation. The quality dimension of work experience refers to the types of experiences one has encountered during this time'.

\section{Method}

\subsection{Sampling Procedures}

A sample of Civil Engineering Master Programme students for the intake years of 2008/2009, 2009/2010 and 2010/2011 was selected. The sources of the data used were students' application forms and academic records regarding the ongoing or final CGPA progress of the students. The application forms furnished data on the previously attended university, UCGPA, work experience and English proficiency. Descriptive statistics were used to analyse demographic data, and correlations were used to determine the contribution of the factors of interest, namely country, UCGPA, previous work experience and English proficiency to the students' later success. Only students from the countries with the highest representation (Malaysia, Iran and Iraq) were included. The UCGPAs of the samples were categorised into three (3) levels as follows: UCGPA less than 2.7, UCGPA between 2.7 and 3.00, and UCGPA greater than 3.00. In terms of work experience, the candidates were classified as either fresh graduates, having up to 4 years of work experience or having more than 4 years of work experience. Regarding the English proficiency requirement at entry level, Malaysian students were exempted due to prior achievement at the undergraduate level. For foreign students, UKM initiated an English requirement in Semester I of the academic year 2009/2010 based on TOEFL/IELTS achievement. However, in this study, the significance of English proficiency towards graduate performance was only assessed for Iranian students because the samples with and without English were adequate for analysis.

\subsection{Measures and Covariates}

To measure the strength of the linear relationship between two variables, Pearson's Correlation is used. The coefficient is usually signified by $r$ (rho) and is valued from -1.0 to 1.0 , where -1.0 is a perfect negative (inverse) correlation, 0.0 is no correlation, and 1.0 is a perfect positive correlation. The statistical significance of $r$ is tested using a t-test. The hypotheses used in this study are as follows:

$$
\begin{aligned}
& \mathrm{H}_{0}: \text { rho }=0 \\
& \mathrm{H}_{\mathrm{a}}: \text { rho }<>0
\end{aligned}
$$

A low p-value for this test (less than 0.05 , for example) means that evidence exists to reject the null hypothesis in favour of the alternative hypothesis; i.e., that a a statistically significant relationship exists between the two variables.

\section{Results and Discussion}

\subsection{Description of the Samples}

Forty-three students entered Sessions 2008/2009, 2009/2010 and 2010/2011. Table 1 shows the distribution of these students according to country and session. 
Table 1. Distribution of students according to country and session

\begin{tabular}{lccccc}
\hline Session & $2008 / 2009$ & $2009 / 2010$ & $2010 / 2011$ & Total & Percentage \\
\hline Malaysia & 4 & 1 & 7 & 12 & 28 \\
Iran & 11 & 4 & 8 & 23 & 53 \\
Iraq & 5 & 0 & 3 & 8 & 19 \\
Students (N) & 20 & 5 & 18 & 43 & 100 \\
\hline
\end{tabular}

Only three (3) countries were chosen because these countries always dominated the student body in all postgraduate programmes in the faculty. The distribution of students according to country was as follows: Malaysia (28\%), Iran (53\%) and Iraq (19\%). Table 2 shows the descriptive statistics of all students for the three factors evaluated in this study.

Table 2. Descriptive statistics for the GCGPA, UCGPA, work experience and English proficiency of all students

\begin{tabular}{lcccccc}
\hline \multirow{2}{*}{ Country } & \multicolumn{2}{c}{ GCGPA } & \multicolumn{2}{c}{ UCGPA } & \multicolumn{2}{c}{ Work experience } \\
\cline { 2 - 7 } & Mean & Std. Dev. & Mean & Std. Dev. & Mean & Std. Dev. \\
\hline Malaysia & 3.58 & 0.26 & 2.88 & 0.42 & 4.11 & 4.03 \\
Iran (without TOEFL/IELTS) & 3.58 & 0.23 & 2.77 & 0.15 & 3.38 & 5.07 \\
Iran (with TOEFL/IELTS) & 3.60 & 0.18 & 3.09 & 0.30 & 2.63 & 3.02 \\
Iraq & 3.52 & 0.23 & 2.69 & 0.22 & 1.87 & 2.53 \\
\hline
\end{tabular}

The average achievements of all students from Malaysia (3.58), Iran (3.60) and Iraq (3.52) were almost comparable. All of the applicants met the entry requirement of 2.7. However, Malaysian students exhibited the highest standard deviation (0.42), indicating that candidates with very low UCGPAs had been accepted into the programme after previous work experience had been considered.

Figure 1 shows that most candidates who enrolled into the programme met the minimum entry requirement but did not meet the high requirement. Candidates with UCGPAs in the range from 2.70 to 3.00 represented $43.5 \%$ of the sample.

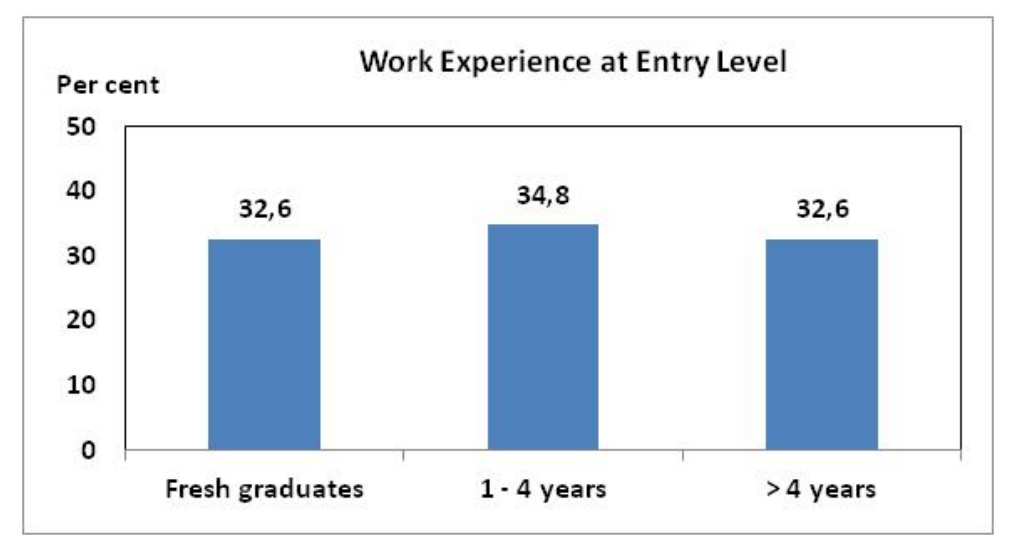

Figure 1. UCGPAs at entry level

Figure 2 shows that most of the students who enrolled in a master's programme had graduated in the past $1-4$ years $(34.8 \%)$. 


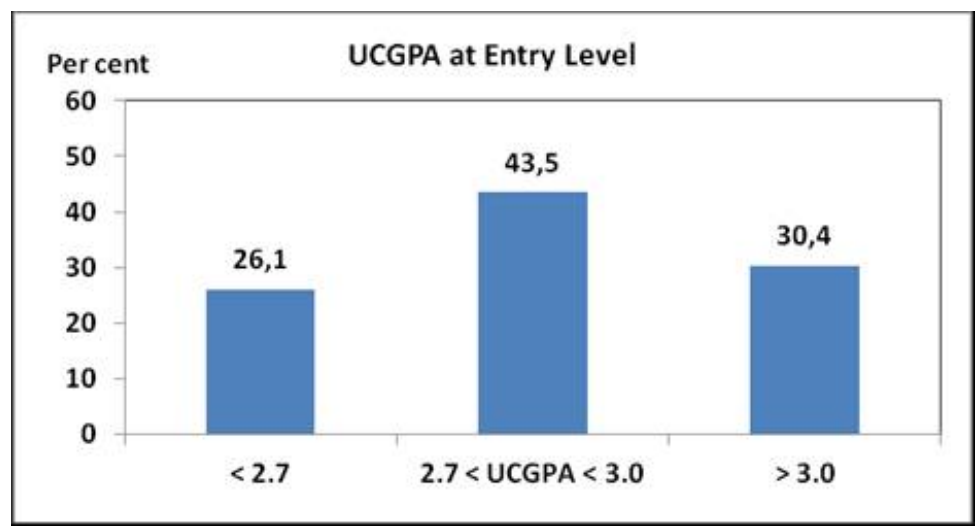

Figure 2. Work experience at entry level

Figure 3 indicates that the sample used for English proficiency was proportional to the number of students present. Malaysian students, who represented $32.6 \%$ of the sample, were not required to provide an English proficiency test score. The percentages of students with and without TOEFL/IELTS scores were $34.8 \%$ and $32.6 \%$, respectively.

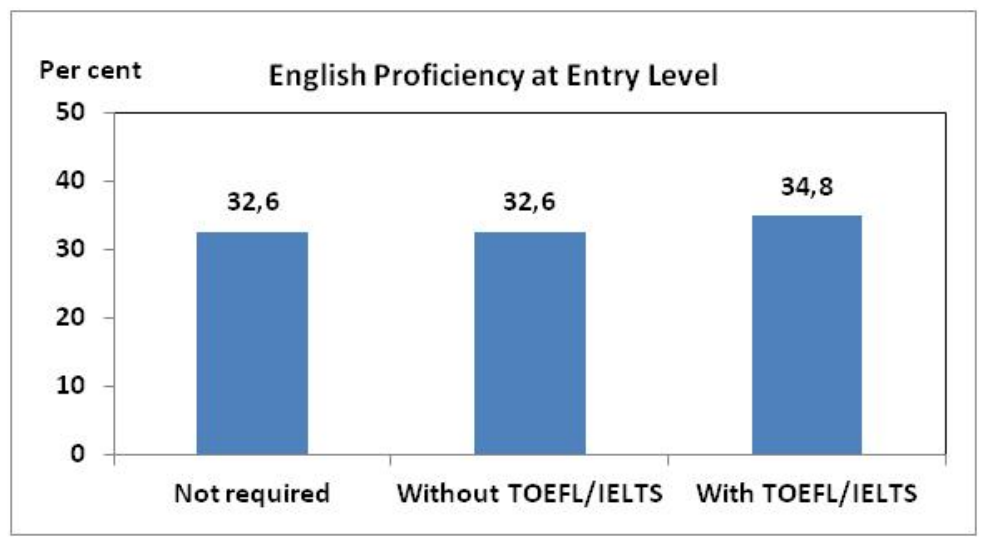

Figure 3. English proficiency at entry level

\subsection{Relationships between GCGPA and UCGPA for Students from Various Countries}

The extent to which UCGPA contributes towards GCGPA was determined using Pearson's correlation method. Table 3 shows the correlations between GCGPA and UCGPA for all countries.

Table 3. Correlations between GCGPA and UCGPA according to country

\begin{tabular}{lccc}
\hline \multicolumn{1}{c}{ Country } & Pearson's Correlation & $p$-value & $\mathrm{N}$ \\
\hline Malaysia & 0.331 & 0.114 & 15 \\
Iran & -0.045 & 0.421 & 22 \\
Iraq & 0.232 & 0.290 & 8 \\
\hline
\end{tabular}

*statistically significant, $p<0.05$ (one-tailed).

Bivariate correlations indicate that the relationships between UCGPA and GCGPA differ for each participating country. For Malaysia, the relationship is weak but higher than those of the other two countries $(\mathrm{r}=0.331, p<0.05)$. The positive correlation indicates that as entry UCGPA increases, GCGPA also tends to increase. The same positive results were found for students from Iraq but with weaker correlations. The correlation found in this study is consistent with that found by Alias and Zain (2006) in similar studies. However, for Iranian students, the UCGPA is not significant and is, in fact, negatively correlated.

\subsection{Relationships between GCGPA and Previous Work Experience from Various Countries}

The bivariate correlation between GCGPA and previous work experience is shown in Table 4 below. 
Table 4. Correlations between GCGPA and previous work experience according to country

\begin{tabular}{lccc}
\hline \multicolumn{1}{c}{ Country } & Pearson's correlation & $p$-value & $\mathrm{N}$ \\
\hline Malaysia & -0.133 & 0.319 & 15 \\
Iran & $0.416^{*}$ & 0.027 & 22 \\
Iraq & 0.232 & 0.290 & 8 \\
\hline
\end{tabular}

*statistically significant, $p<0.05$ (one-tailed).

For students from Malaysia, previous work experience is not significant to GCGPA and is, in fact, negatively correlated $(-0.133)$. This means that freshly graduated students performed better. One possible disadvantage faced by candidates who have left college for several years could be the inability to recall fundamental theories learned at the undergraduate level. Another disadvantage could be a decrease of the level of commitment that they can devote to their study because most of these senior candidates have larger families and more responsibilities than the younger candidates. Therefore, this work experience factor cannot be duly interpreted by itself because family commitment could be the major factor causing the lower performance of the senior students. Further studies should reveal whether this is the case. However, work experience appears to contribute positively to the performance of graduate students from Iraq and Iran in the programme. For Iranian students especially, this factor becomes very significant $(\mathrm{r}=0.416, p<0.05)$. It is probable that the work environment for students from Iran who continued their studies involved students from academic and research backgrounds. A more detailed study should be carried out to determine the type of experience that the applicants are involved in.

\subsection{Relationships between GCGPA and English Proficiency for Iranian students}

Starting from Semester I 2009/2010, international students were required to demonstrate their English proficiency based on TOEFL/IELTS scores. The minimum TOEFL score required by the faculty was 550, and the minimum IELTS requirement was 6.0. Table 5 shows the descriptive statistics of the GCGPAs, comparing those with English proficiency results to those without these scores.

Table 5. Correlation coefficients between GCGPA and English Proficiency scores for Iranian students

\begin{tabular}{lccc}
\hline & & Without TOEFL/IELTS scores & With TOEFL/IELTS scores \\
\hline $\begin{array}{l}\text { Correlation between } \\
\text { experience and GCGPA }\end{array}$ & work & $0.50^{*}$ & 0.22 \\
\hline $\mathrm{N}$ & & 10 & 12 \\
\hline
\end{tabular}

*statistically significant, $p<0.05$ (one-tailed).

Table 5 indicates that English proficiency affects the results of the study because the correlation between work experience and GCGPA differs for students with and without TOEFL scores. Work experience and GCGPA were highly correlated $(\mathrm{r}=0.50)$ for students without English proficiency scores. The reason is that work experience contributed to English proficiency and thus helped to improve students' grades when they continued their studies.

\section{Conclusion}

As a result of this study, the University will be better informed regarding the interaction between GCGPA and entry requirements, such as UCGPA, work experience, English score and country of origin. Therefore, the faculty can take appropriate steps during the selection of graduate candidates. The data appear to support the following conclusions:

1) The factors contributing to the performance of students from different countries differ, indicating that student background cannot be disregarded.

2) Most candidates who enrolled into the programme were not high achievers at the undergraduate level.

3) UCGPA and previous work experience show both positive and negative contributions to GCGPA.

Regarding student intake into the master's programme, the findings obtained in this study strongly suggest that UCGPA should no longer be used as the sole criterion for admission.

\section{Acknowledgements}

This work was supported by Research Grants PTS-2011-150 and OUP-2012-126. The authors would like to 
thank the Centre of Engineering Education at Universiti Kebangsaan Malaysia, Bangi for their support with this study.

\section{References}

Alias M., \& Mohd. Zain, A. F. (2006). Relationship between entry qualifications and performance in graduate education. International Education Journal, 7(3), 371-378.

Arsad, P. M., Buniyamin, N., \& Ab Manan, J. (2011). Profiling the performance of electrical engineering bachelor degree students based on different entry levels. International Journal of Education and Information Technologies, 5(2), 267-274.

Braunstein, A. W. (2002, September). Factors determining success in a graduate business program. College Student Journal.

Academic Regulation, UiTM (2009). 2009 Edition.

DeRue, D. S. (2009). Quantity or Quality? Work Experience as a Predictor of MBA Student Success. GMAC Research Reports, RR-09-09 September 2.

Kuncel, N. R., Hezlett, S. A., \& Ones, D. S. (2001). A comprehensive meta-analysis of the predictive validity of the graduate record examinations implications for graduate student selection and performance. Psychological Bulletin, 127(1), 162-181. http://dx.doi.org/10.1037/0033-2909.127.1.162

Lane J., Lane, A., \& Cockerton, T. (2003). Prediction of postgraduate performance from self-efficacy, class of degree and cognitive ability test scores. Journal of Hospitality, Leisure, Sport and Tourism Education, 2(1), 113-118. http://dx.doi.org/10.3794/johlste.21.16

Rende, D., Rende, S., \& Baysal, N. (2006). Factors predicting the perfromance of engineering students: a case study from Yeditepe University. 9th International Engineering Education, M4F-8, July 23-28.

Self Assesment Report. (2011). Master of Engineering (Civil Engineering), Faculty of Engineering and Built Environment UKM.

Truitt, T. C. (2002). Validity of selection criteria in predicting MBA success. CBFA Conference 2002, Anderson University. Retrieved April 11, 2006, from http://www.cbfa.org/papers/2002 livefaith/Truitt.doc

Wardlow, G. (1989). International students of agricultrure in U.S. institutions: Precursors to academic success. Journal of Agriculture Education, 17-22. 